\title{
$\$$ Research Square \\ Nd:YAG low-level laser treatment in burning mouth syndrome: a pilot study
}

\section{Chen Sun}

Shanghai Jiao Tong University School of Medicine

\section{Pan Xu}

Shanghai Jiao Tong University School of Medicine

\section{Qian-Qian Zhang}

Shanghai Jiao Tong University School of Medicine

Wei-Wen Jiang ( $\nabla$ wwjiang33@hotmail.com )

Shanghai Jiao Tong University School of Medicine https://orcid.org/0000-0002-9738-3989

\section{Research article}

Keywords: Burning mouth syndrome, Nd: YAG, Low-level laser

Posted Date: January 3rd, 2020

DOI: https://doi.org/10.21203/rs.2.19620/v1

License: (9) This work is licensed under a Creative Commons Attribution 4.0 International License. Read Full License 


\section{Abstract}

Background : Burning mouth syndrome (BMS) is chronic disorder characterized by pain/burning sensation in oral cavity. Nd:YAG low-level laser (LLL) has been used in the treatment of pain reduction. The aim of this study was to assess the effectiveness of LLL verse no power placebo with Nd:YAG in the treatment of patients with BMS in pain/burning, numbness and altered taste.

Methods : Forty-two patients with BMS were randomly equally assigned into LLL group and placebo group. The parameters of Nd:YAG irradiation consisted of $100 \mathrm{~mW}$ power, $3 \mathrm{~J} / \mathrm{cm} 2$ energy density, $10 \mathrm{~Hz}$, pulse mode and a 1064nm wavelength emission. The placebo group used the same LLL instrument which was switched off. Each patient underwent one laser irradiation session per week for 4 weeks. Clinical assessment of subjective pain/burning, numbness and altered taste was performed using a visual analogue score (VAS) before each irradiation session and one week after last treatment.

Results : All of patients (21) was showed significant decreasing of VAS value of pain/burning (ranged from $2 \% \sim 100 \%$, mean $52 \%$ ) after 4-weeks LLL treatment. The improvement of VAS value of numbness in LLL group (ranged from $23 \% \sim 100 \%$, mean $61 \%$ ) was significant from the baseline to the end of LLL treatment. Relief of altered taste was found neither in LLL group nor in placebo group. All patients completed this study and none of them reported adverse effects.

Conclusions : Nd:YAG LLL (100mw, 3J/cm 2, $10 \mathrm{~Hz}))$ was effective for reduction of pain/burning and numbness in patients with BMS.

\section{Background}

Burning mouth syndrome (BMS) is a chronic disorder characterized by pain/burning sensation in oral cavity [1]. Some patients also suffer numbness, and/or altered taste [2, 3]. The most affected site of oral cavity is tongue, probably company with lips, and hard palate $[4,5]$. The prevalence of BMS is $0.1-3.9 \%$ [6] and is relatively higher within the group of pre- and post-menopausal women [7]. The possible causal factors are neuropathy, psychology, oral candidiasis, hormonal disorder related with menopause, and nutritional deficiencies [8]. A trigeminal small-fiber sensory neuropathy in BMS was evidenced by diffuse degeneration of epithelial and sub-papillary nerve fibers of anterior two-third of tongue [9]. Thalamus hypoactivity has been described in BMS [10] and other neuropathic pain conditions [11], which suggesting the CNS in complex pain modulation networks. Even if numerous previous studies are about BMS, its pathogen is still uncertain which related to the difficulty in successfully treating BMS patients. Till now, a variety of drugs, and miscellaneous treatments have been applied in BMS patients [12]; however, the satisfaction of management of this syndrome is still not reached.

Recently, low-level laser (LLL) treatment has showed the benefit in pain relief including patient with BMS $[13,14]$. The analgesic effect probably attributes to increasing the pain threshold, decreasing endogenous opiates, and regulating the release of pain mediators [15-17]. Arbabi-Kalati et al treated BMS patients using lodine-Gallium-Arsenide (loGaAs) LLL with $810 \mathrm{~nm}$ wavelength [18] and showed a significant 
improvement of pain relief. Arduino et al selected Aluminum-Gallium-Arsenide (AlGaAs) LLL of with $980 \mathrm{~nm}$ wavelength comparing with control of clonazepam treatment in patients with BMS [19]. Patients in AlGaAs LLL group showed a significant decrease of pain/burning sensation, compared with control group did.

The neodymium-doped yttrium aluminum garnet (Nd:YAG) with $1064 \mathrm{~nm}$ wavelength has an advantage in penetrating deeply to the target tissue. However, little is known for its effectiveness in managing patients with BMS. The aim of this study was to assess the effectiveness of Nd:YAG LLL verse no power placebo in the treatment of patients with BMS in pain/burning, numbness and altered taste.

\section{Methods}

\section{Participants}

Patients were recruited at Department of Oral Mucosal Diseases, Shanghai Ninth People's Hospital during July of 2018 to June of 2019. The protocol was approved by Committee of Medical Ethics of the hospital (SH9H-2018-T18-2). The written informed consent was obtained from all patients. And, the trial was registered at Chinese Clinical Trial Registry (ChiCTR1800018834).

Inclusion criteria were as follows: (1) patients diagnosed as BMS in accordance with the International Association for the Study of Pain (IASP) [1] which characterized this syndrome as oral burning sensation without detectable organic lesion in oral cavity; (2) symptom of burning sensation only on the tongue; and (3) ability to complete the clinical trial.

Exclusion criteria: patients (1) with oral pain accompanied with detectable organic lesion in oral mucosa; (2) diagnosed as BMS but symptom of burning sensation was outside the tongue; (3) a history of psychosis; pregnancy or breast-feeding women; and (4) reluctance to give consent to participate.

Laboratory examinations were also performed including blood routine examination, blood glucose, serum iron, total iron binding capacity, iron saturation, vitamin B12, folic acid, 25-OH-D3, fungal culture, and allergic text. All enrolled BMS patients were arranged to have laboratory examinations at the end of treatment. Individuals with abnormal laboratory values were kept as "enrolled participant", but modified diagnosis as " secondary" BMS and treated accordingly.

\section{Study design}

\section{Randomization}

This randomized controlled trial (RCT) was single-blind, single-center, and parallel study. Patients were assigned to one of two groups by a computer program using simple sequentially numbered randomization table. The assignation number was uniformly kept in a sealed envelope until the moment 
of treatment. Participates were allowed to abandon the trial at any time if they no long wanted to receive therapy.

\section{Sample size}

Sample size was not estimated because of the lack of any studies using $1064 \mathrm{~nm}$ Nd:YAG LLL treatment for BMS. Therefore, we arbitrarily decided to enrolled minimum 21 patients in each group for this pilot study.

\section{Treatment modalities}

Patients were randomly assigned to two groups: LLL group, the patients were irradiated with a Nd:YAG laser ( HSM-囚,Sichuan Aerospace Sid Control \& Guide Co,. Ltd, China), according to the manufacturer's instructions, and placebo group, the patients was treated under the same LLL instrument which was switched off.. The tongue was divided into 17 treatment regions (Fig. 1). The number of treatment region was depended on the extents of tongue affected. Before laser irradiation, the treatment areas were cleaned with normal saline and dried with gauze. The probe was applied vertically over mucosa at a distance of about $0.6 \mathrm{~cm}$ where the irradiation area was $1 \mathrm{~cm}^{2}$. The parameters of irradiation consisted of $100 \mathrm{~mW}$ power, $3 \mathrm{~J} / \mathrm{cm}^{2}$ energy density, $10 \mathrm{~Hz}$, pulse mode and a $1064 \mathrm{~nm}$ wavelength emission. Each patient underwent one laser irradiation session per week for 4 weeks.

\section{Clinical assessment}

Clinical assessment of subjective pain/burning, numbness and altered taste was performed using a visual analogue score (VAS), which consisting of a $10 \mathrm{~cm}$ vertical line marked with 0 (absence of symptom) to 10 (the most severe symptom), right before each irradiation session and one week after last treatment.

The primary outcome of the study was the effectiveness of LLL treatment for pain/burning relief between baseline and the last session. The secondary outcomes were the effectiveness of LLL treatment in relief of numbness and altered taste. The effectiveness of LLL treatment was defined as the mean percentage of improvement in symptom and calculated using the following formula:

Effectiveness (\%) $=\left(\mathrm{VAS}_{\text {baseline }}-\mathrm{VAS}_{\text {session }}\right) \times 100 / \mathrm{VAS}_{\text {baseline }}$ 
Statistical analysis was performed using SPSS, version 24 (SPSS Inc, Chicago, Illinois). Basic variables including gender, systemic disease and menopause were analyzed using Chi-square test. Basic features including age and VAS of symptom were accessed by independent 2-sample $t$ test. Non-normal distribution variable, diseases duration, was analyzed by Wilcoxon rank sum test. Comparison of VAS in either inter-group or intra-group for each session was analyzed by repeated-measures analysis of variance (ANOVA). Statistically significant deference was established as $P<0.05$.

\section{Results}

\section{General information of the trail}

Forty-four BMS patients were screened and 2 patients were not included. One patient declined to participate and one patient had a diagnosis of psychosis. Finally, a total of 42 patients with BMS including $34(81 \%)$ women and $8(19 \%)$ men with average disease duration of 9 months, ranging from 2 to 60 months, were enrolled for the study from October of 2018 to September of 2019 (Table 1). The mean age was 51.69 years, ranging between 19 and 71 years (Table 1). Among these participants, 30 reported systemic disease (supplementary Table 1). Every 21 patients were randomized into LLL and placebo group. After laboratory examination, 10 and 13 participants in LLL and placebo group, respectively. The flow diagram of the trial is showed in Fig. 2. 
Table 1

Baseline characteristics

\begin{tabular}{|c|c|c|c|c|}
\hline Variables & Total & LLL & Placebo & $\mathbf{P}$ \\
\hline \multicolumn{5}{|l|}{ Gender (n) } \\
\hline Female & 34 & 19 & 15 & 0.24 \\
\hline Male & 8 & 2 & 6 & \\
\hline Age, mean (years) & 51.69 & 56.19 & 47 & 0.06 \\
\hline Disease duration, mean (months) & 9 & 11.80 & 7.00 & 0.31 \\
\hline \multicolumn{5}{|l|}{ Systemic disease (n) } \\
\hline & 30 & 17 & 13 & 0.17 \\
\hline \multicolumn{5}{|l|}{ Menopause (n) } \\
\hline & 26 & 16 & 10 & 0.11 \\
\hline \multicolumn{5}{|l|}{ Pain/Burning (n) } \\
\hline & 42 & 21 & 21 & 1.00 \\
\hline \multicolumn{5}{|l|}{ Numbness (n) } \\
\hline & 22 & 14 & 8 & 0.06 \\
\hline \multicolumn{5}{|l|}{ altered taste $(n)$} \\
\hline & 6 & 4 & 2 & 0.38 \\
\hline Pain/Burning (VAS) & $4.29 \pm 1.59$ & $4.55 \pm 1.67$ & $4.06 \pm 1.49$ & 0.33 \\
\hline Numbness (VAS) & $3.95 \pm 1.70$ & $4.00 \pm 1.55$ & $3.86 \pm 2.15$ & 0.86 \\
\hline Alter taste (VAS) & $3.48 \pm 2.54$ & $2.34 \pm 1.64$ & $5.75 \pm 3.89$ & 0.18 \\
\hline
\end{tabular}

No significant difference of baseline variables were observed (Table 1). All of them completed the study. No adverse effects were reported. No deviations of trial protocol were made after enrollment.

\section{Primary outcome analysis}

All of patients (21) was showed significant decreasing of VAS values of pain/burning (ranged from $2 \%$ $\sim 100 \%$, mean $52 \%$ ) after LLL treatment (Table 2, Supplementary Table 2). The mean VAS value of pain/burning for patients decreased $21 \%, 22 \%, 38 \%$ and $52 \%$, respectively (Supplementary Table 2), significantly from the baseline session ( $\mathrm{S}_{\text {baseline }}$ ) to one week after 1st session (S1), 2nd session (S2), 3rd session (S3) and 4th session (S4) of LLL treatment (Table 2, Supplementary Table 2). The significant 
difference of VAS in pain/burning was also observed between LLL and placebo groups at $S 3(P<0.05)$ and S4 $(P<0.01)$ (Fig. 3A, Table 2).

Table 2

Comparison of VAS (mean \pm SD) between two groups \& each session

\begin{tabular}{|c|c|c|c|c|c|}
\hline Symptom & $S_{\text {baseline }}$ & $\mathrm{S} 1\left(\mathrm{P}^{\mathrm{S1}}\right)$ & $\mathrm{S} 2\left(\mathrm{P}^{\mathrm{S} 2}\right)$ & S3(PS3) & $\mathrm{S} 4\left(\mathrm{P}^{\mathrm{S} 4}\right)$ \\
\hline \multicolumn{6}{|c|}{ Pain/Burning } \\
\hline $\begin{array}{l}\mathrm{LLL} \\
(\mathrm{n}=21)\end{array}$ & $4.55 \pm 1.67$ & $\begin{array}{l}3.60 \pm 1.69 \\
(<0.01)\end{array}$ & $\begin{array}{l}3.56 \pm 1.67 \\
(<0.05)\end{array}$ & $\begin{array}{l}2.80 \pm 1.49 \\
(<0.01)\end{array}$ & $\begin{array}{l}2.19 \pm 1.15 \\
(<0.01)\end{array}$ \\
\hline $\begin{array}{l}\text { Placebo } \\
(n=21)\end{array}$ & $4.06 \pm 1.49$ & $\begin{array}{l}3.64 \pm 1.18 \\
(>0.05)\end{array}$ & $\begin{array}{l}3.53 \pm 1.22 \\
(>0.05)\end{array}$ & $\begin{array}{l}3.80 \pm 1.49 \\
(0.05)\end{array}$ & $\begin{array}{l}3.64 \pm 1.41 \\
(>0.05)\end{array}$ \\
\hline $\mathrm{P}^{\mathrm{g}}$ & $>0.05$ & $>0.05$ & $>0.05$ & $<0.05$ & $<0.01$ \\
\hline \multicolumn{6}{|l|}{ Numbness } \\
\hline $\begin{array}{l}\text { LLL } \\
(n=14)\end{array}$ & $4.01 \pm 1.55$ & $\begin{array}{l}4.01 \pm 1.29 \\
(>0.05)\end{array}$ & $\begin{array}{l}3.02 \pm 1.19 \\
(<0.05)\end{array}$ & $\begin{array}{l}2.91 \pm 1.14 \\
(<0.05)\end{array}$ & $\begin{array}{l}1.47 \pm 1.26 \\
(<0.01)\end{array}$ \\
\hline $\begin{array}{l}\text { Placebo } \\
(n=8)\end{array}$ & $3.86 \pm 2.15$ & $\begin{array}{l}3.81 \pm 1.85 \\
(>0.05)\end{array}$ & $\begin{array}{l}3.45 \pm 2.00 \\
(>0.05)\end{array}$ & $\begin{array}{l}3.26 \pm 1.78 \\
(>0.05)\end{array}$ & $\begin{array}{l}3.55 \pm 2.39 \\
(>0.05)\end{array}$ \\
\hline $\mathrm{Pg}$ & $>0.05$ & $>0.05$ & $>0.05$ & $>0.05$ & $<0.05$ \\
\hline \multicolumn{6}{|c|}{ Altered taste } \\
\hline $\begin{array}{l}\text { LLL } \\
(n=4)\end{array}$ & $2.34 \pm 1.64$ & $\begin{array}{l}0.70 \pm 1.40 \\
(>0.05)\end{array}$ & $\begin{array}{l}0.98 \pm 1.95 \\
(>0.05)\end{array}$ & $\begin{array}{l}1.23 \pm 2.45 \\
(>0.05)\end{array}$ & $\begin{array}{l}0.87 \pm 1.44 \\
(>0.05)\end{array}$ \\
\hline $\begin{array}{l}\text { Placebo } \\
(n=2)\end{array}$ & $5.75 \pm 3.89$ & $\begin{array}{l}1.5 \pm 2.12 \\
(>0.05)\end{array}$ & $\begin{array}{l}2.00 \pm 2.82 \\
(>0.05)\end{array}$ & $\begin{array}{l}2.50 \pm 3.54 \\
(>0.05)\end{array}$ & $\begin{array}{l}2.50 \pm 3.54 \\
(>0.05)\end{array}$ \\
\hline $\mathrm{Pg}$ & $>0.05$ & $>0.05$ & $>0.05$ & $>0.05$ & $>0.05$ \\
\hline
\end{tabular}

S, session; LLL, low-level laser; $P^{S}, P$ of comparison between baseline and each session for a group itself; $\mathrm{Pg}, \mathrm{P}$ of comparison between LLL and placebo group; $\mathrm{n}$, number of patient.

\section{Secondary outcomes}

The mean VAS value of numbness only decreased significantly from the baseline to the end of LLL treatment in LLL group (ranged from 23\% 100\%, mean 61\%) (Fig. 3B). The significant difference was also observed for inter-group comparison. Relief of altered taste was found neither in LLL group nor in placebo group (Fig. 3C, Table 2).

\section{Discussion}


With the properties of analgesic, anti-inflammatory, and bio-stimulation, LLL showed effect in the treatment of pain relief [20-24]. The present study assessed the effectiveness in the Nd:YAG LLL treatment of patients with BMS. BMS patients showed up to $100 \%$ pain/burning relief with mean improvement of $52 \%$ after 4 weeks Nd:YAG LLL treatment.

The pathology of BMS is complex, and may be caused by oral candidiasis, hormonal disorder related with menopause, and nutritional deficiencies, peripheral and central nervous systems disorders, and psychosocial aspect [8]. The diagnose and classification of BMS are first challenges when a patient complains the symptom of burning/pain in the mouth. According to Headache Classification Committee of the International Headache Society, whether secondary BMS attributed to a local factors such as candidiasis or systemic disorders should be considered as an entity is a matter for debate [25]. As well, it is not clear after eliminating these factors (such as candidasis, anemia) whether the symptom of pain/burning can be relieved. Therefore, we utilized the BMS definition of IASP, which being burning tongue or other mucous membranes without organic oral lesion [1]. Meanwhile, we performed laboratory test after LLL treatment (blind for secondary BMS) and found that 10 and 13 patients in LLL and placebo were abnormal in laboratory test, respectively. Combining 30 patients with systemic disease in the recruitment, in total 21 and 19 patients in the LLL group and placebo group could be related to "secondary" BMS, respectively. This indicated that Nd:YAG LLL was effective for patients with BMS even if those were with possible systemic conditions.

Different wavelengths, such as $660 \mathrm{~nm}$ Indium-Gallium-Aluminum-Phosphorus (InGaAlP) [26-28], $685 \mathrm{~nm}$ Gallium-Aluminum-Arsenic (GaAlAr) [29], 790-830 nm Gallium-Aluminum-Arsenide (GaAlAs) [13, 30-34], $910 \mathrm{~nm}$ Gallium-Arsenide (GaAs) [35] and $980 \mathrm{~nm}$ AlGaAs [19], have been suggested as being effective in managing BMS. Whether laser effect is dependent upon the wavelength of the light is still unclear. Demirkol et al using Nd:YAG laser obtained better results in the treatment of subjective tinnitus related to temporomandibular joint disorders comparing with diode LLL did, probably because of the $\mathrm{Nd}$ :YAG laser having a wavelength of $1046 \mathrm{~nm}$ that permits it to penetrate deeply and extend readily within tissue [24]. Our study provided the evidence that Nd:YAG LLL treatment was an effective approach for BMS patients relieving pain/burning.

Hansen et al using red diode LLL treating BMS patients with a laser switched-off control group [36]. LLL as well as switch-off Laser decreased symptom of pain in the same manner. Placebo response was also evidenced to be effective in other study approximately $7.3 \% \sim 50 \%$ of the patients $[13,15,30,37]$. It was suggested that a psychosomatic organ of pain might resulted in the possibility of placebo effect [31]. Therefore, we eliminated the BMS patients with a history of psychosis in our trial screening process. Our data showed significant difference of treatment between LLL and placebo group. And, patients in placebo group did not show clinical significance.

The function of the taste buds depends on the type of papillae and the region in which they are located [38]. In mammals, taste papillae include fungiform papillae, circumvalate papillae and foliate papillae. The fungiform papillae are located at the apex and body of tongue and contains taste buds involving the 
sweet and sour tastes, controlled by fibers of the lingual nerve. The circumvallate papillae are distributed at the root of the tongue and its taste buds receives bitter signal through sensory fibers of the glossopharyngeal nerve. The foliate papillae are sit at the lateral surfaces of the posterior tongue. The taste buds of foliate papillae react primarily to the sour taste and are innervated by branches of the chorda tympani nerve and glossopharyngeal nerve. Palatine taste buds are controlled by the branch of the facial nerve [38]. Overall, the largest number of taste buds is at the tongue and palate, while some at the epiglottis, throat and larynx [39]. Our study, irradiation was performed within 17 area (Fig. 1), in which mainly before the circumvallate papillae. This may explain treatment of altered taste was not effective.

\section{Conclusions}

It can be concluded that Nd:YAG LLL $\left(3 \mathrm{~J} / \mathrm{cm}^{2}, 30 \mathrm{~s}\right.$, and $\left.100 \mathrm{~mW}\right)$ was effective for reduction of pain/burning and numbness in patients with BMS.

\section{Abbreviations}

BMS: burning mouth syndrome; LLL: low-level laser; RCT: randomized controlled trial; VAS: visual analogue scale; $S_{\text {baseline: }}$ baseline session; S1: $1^{\text {st }}$ session; S2: $2^{\text {nd }}$ session; S3: $3^{\text {rd }}$ session; S4: $4^{\text {th }}$ session; Nd:YAG: neodymium-doped yttrium aluminum garnet; loGaAs: lodine-Gallium-Arsenide; AIGaAs: Aluminum-Gallium-Arsenide; InGaAIP: Indium-Gallium-Aluminum-Phosphorus; GaAIAr: GalliumAluminum-Arsenic; GaAlAs: Gallium-Aluminum-Arsenide; GaAs: Gallium-Arsenide; IASP: the International Association for the Study of Pain.

\section{Declarations}

\section{Acknowledgments}

The authors thank Dr Zhenyu Wu, Department of Biostatistics of Fudan University, for assistance in statistical analysis and thank the participating patients.

\section{Funding}

This work was supported by National Natural Science Foundation of China (No. 81671036).

\section{Availability of data and materials}

The datasets used and analyzed during the current study are available from the corresponding author on reasonable request. 


\section{Authors' contributions}

WW Jiang designed and analyzed the study, C Sun contributed to the writing and revision of the manuscript, C Sun and QQ Zhang contributed to statistical analysis, and P Xu contributed to collection of data. All authors read and approved the final manuscript.

\section{Ethics approval and consent to participate}

The study was approved by Committee of Medical Ethics of Shanghai Ninth People's Hospital (SH9H2018-T18-2). Written informed consent was obtained from all patients.

\section{Consent for publication}

Not applicable.

\section{Competing interests}

The authors declare that they have no competing interests

\section{Publisher's Note}

Springer Nature remains neutral with regard to jurisdictional claims in published maps and institutional affiliations

\section{References}

1. The International Association for the Study of Pain. Descriptions of chronic pain syndromes and definitions of pain terms. In: Harold Merskey, N Bogduk, editors. Classification of chronic pain. 1994. p.74-75.

2. Lopez-Jornet P, Molino-Pagan D, Parra-Perez P, Valenzuela S.Neuropathic Pain in Patients with Burning Mouth Syndrome Evaluated Using pain DETECT. Pain Med. 2017;18:1528-1533.

3. Nagler RM, Hershkovich 0 . Sialochemical and gustatory analysis in patients with oral sensory complaints. J Pain.2004;5:56-63.

4. Lamey PJ. Burning mouth syndrome. Dermatol Clin. 1996;14:339-54. 
5. Lamey PJ, Lamb AB. Lip component of burning mouth syndrome. Oral Surg Oral Med Oral Pathol. 1994;78:590- 3.

6. Zakrzewska JM, Forssell H, Glenny AM. Interventions for the treatment of Burning mouth syndrome. Cochrane database Syst Review. 2005;doi: 10.1002/14651858.CD011259.pub2.

7. Meurman JH, Tarkkila L, Tiitinen A. The menopause and oral health. Maturitas. 2009;63(1):56-62.

8. Vellappally S. Burning Mouth Syndrome: A Review of the Etiopathologic Factors and Management. J Contemp Dent Pract. 2016;17:171-6.

9. Lauria G, Majorana A, Borgna M, Lombardi R, Penza P, Padovani A, et al. Trigeminal small-fiber sensory neuropathy causes burning mouth syndrome. Pain. 2005;115:332-337.

10. Albuquerque RJ, de Leeuw R, Carlson CR, Okeson JP, Miller CS, Andersen AH. Cerebral activation during thermal stimulation of patients who have burning mouth disorder: an fMRI study. Pain. 2006;122:223-34.

11. Hsieh JC, Belfrage M, Stone-Elander S, Hansson P, Ingvar M. Central representation of chronic ongoing neuropathic pain studied by positron emission tomography. Pain. 1995;63:225-36.

12. Liu YF, Kim Y, Yoo T, Han P, Inman JC. Burning mouth syndrome: a systematic review of treatments. Oral Dis. 2018;24:325-334.

13. Cui D, Zhang Y. Efficacy of low-level laser therapy in the treatment of burning mouthsyndrome. Chinese Journal of Practical Stomatology. 2017;10:158-162.

14. Al-Maweri S, Javed F, Kalakonda B, et al. Efficacy of low level laser therapy in the treatment of burning mouth syndrome: A systematic review. Photodiagnosis and photodynamic therapy. 2017;17:188-193.

15. Cammarata F, Wautelet M. Medical lasers and laser-tissue interactions. Phys Educ. 1999;34:156-161.

16. Bittencourt MA, Paranhos LR, Martins-Filho PR. Low-level laser therapy for treatment of neurosensory disorders after orthognathic surgery: A systematic review of randomized clinical trials. Medicina oral, patologia oral cirugia bucal. 2017;22:780-787.

17. de Andrade AL, Bossini PS, Parizotto NA. Use of low level laser therapy to control neuropathic pain: A systematic review. Journal of photochemistry and photobiology. 2016;164:36-42.

18. Arbabi-Kalati F, Bakhshani N,Rasti M. Evaluation of the efficacy of low-level laser in improving the symptoms of burning mouth syndrome. Journal of clinical and experimental dentistry. 2015;7:e524e527.

19. Arduino P, Cafaro A, Garrone M, Gambino A, Cabras M, Romagnoli E, et al. A randomized pilot study to assess the safety and the value of low-level laser therapy versus clonazepam in patients with burning mouth syndrome. Lasers in medical science. 2016;31:811-816.

20. Carrasco TG, Guerisoli LD, Guerisoli DM, Mazzetto MO. Evaluation of low intensity laser therapy in myofascial pain syndrome. Cranio. 2009;27:243-7.

21. Carvalho CM, de Lacerda JA, dos Santos Neto FP, Cangussu MC, Marques AM, Pinheiro AL. Wavelength effect in temporomandibular joint pain: a clinical experience. Lasers Med Sci. 
2010;25:229-32.

22. Katsoulis J, Ausfeld-Hafter B, Windecker-Gétaz I, Katsoulis K, Blagojevic N, Mericske-Stern R. Laser acupuncture for myofascial pain of the masticatory muscles. A controlled pilot study. Schweiz Monatsschr Zahnmed. 2010;120:213-225.

23. López-Ramírez M1, Vílchez-Pérez MA, Gargallo-Albiol J, Arnabat-Domínguez J, Gay-Escoda C. Efficacy of low-level laser therapy in the management of pain, facial swelling, and postoperative trismus after a lower third molar extraction. A preliminary study. Lasers Med Sci. 2012;27:559-66.

24. Demirkol N, Usumez A, Demirkol M, Sari F, Akcaboy C. Efficacy of Low-Level Laser Therapy in Subjective Tinnitus Patients with Temporomandibular Disorders. Photomed Laser Surg. 2017;35:427-431.

25. Headache Classification Committee of the International Headache Society (IHS). The international classification of headache disorders, 3rd edition (beta version). Cephalagia 2013;33:629-808.

26. Brailo V, Bosnjak A, Boras VV, Jurisic AK, Pelivan I, Kraljevic-Simunkovic S. Laser acupuncture in the treatment of burning mouth syndrome: a pilot study. Acupunct Med 2013;31:453-4.

27. Santos-Lde F, de-Andrade S, Nogueira G, Leão JC2, de Freitas PM3. Phototherapy on the Treatment of Burning Mouth Syndrome: A Prospective Analysis of 20 Cases. Photochemistry and photobiology. 2015;91:1231-1236

28. Barbosa NG, Gonzaga AKG, de Sena Fernandes LL, da Fonseca AG, Queiroz SIML, Lemos TMAM, et al. Evaluation of laser therapy and alpha-lipoic acid for the treatment of burning mouth syndrome: a randomized clinical trial. Lasers Med Sci 2018;33:1255-62.

29. Pezelj-Ribaric S, Kqiku L, Brumini G, Urek MM, Antonić R, Kuiš D, et al. Proinflammatory cytokine levels in saliva in patients with burning mouth syndrome before and after treatment with low-level laser therapy. Lasers Med Sci 2013;28:297-301.

30. Sugaya N, Silva E, Kato I, Prates R, Gallo CB, Pellegrini VD, et al. Low Intensity laser therapy in patients with burning mouth syndrome: a randomized, placebo-controlled study. Brazilian oral research. 2016;30:e108.

31. Valenzuela S, Lopez-Jornet P. Effects of low-level laser therapy on burning mouth syndrome. Journal of oral rehabilitation. 2017;44:125-132.

32. Kato I, Pellegrini V, Prates R, et al. Low-level laser therapy in burning mouth syndrome patients: a pilot study. Photomed Laser Surg 2010;28:835-9.

33. Yang $\mathrm{H}$, Huang Y. Treatment of burning mouth syndrome with a low-level energy diode laser. Photomedicine and laser surgery. 2011;29:123-125.

34. Spanemberg J, JLopez-Lopez, de-Figueiredo M, et al. Efficacy of low-level laser therapy for the treatment of burning mouth syndrome: a randomized, controlled trial. Journal of biomedical optics. 2015;20:098001.

35. Romeo U, Del-Vecchio A, Capocci M, et al. The low level laser therapy in the management of neurological burning mouth syndrome. A pilot study. Ann Stomatol (Roma) 2010;1:14-18. 
36. Hansen HJ, Thorøe U. Low power laser biostimulation of chronic oro-facial pain. A double-blind placebo controlled cross-over study in 40 patients. Pain. 1990;43:169-179.

37. Vukoja D, Alajbeg I, Boras V, Brailo V, Alajbeg IZ, Andabak Rogulj A. Is effect of low-level laser therapy in patients with burning mouth syndrome result of a placebo? Photomedicine and laser surgery. 2011;29:647-648.

38. Kikut-Ligaj D, Trzcielińska-Lorych J. How taste works: cells, receptors and gustatory perception. Cell Mol Biol Lett. 2015;20:699-716.

39. Randall R. Reed, Andrew P. Lane. Handbook of olfaction and gustation. Neurological Disease and Therapy. 2013;57:1693-1694

\section{Figures}
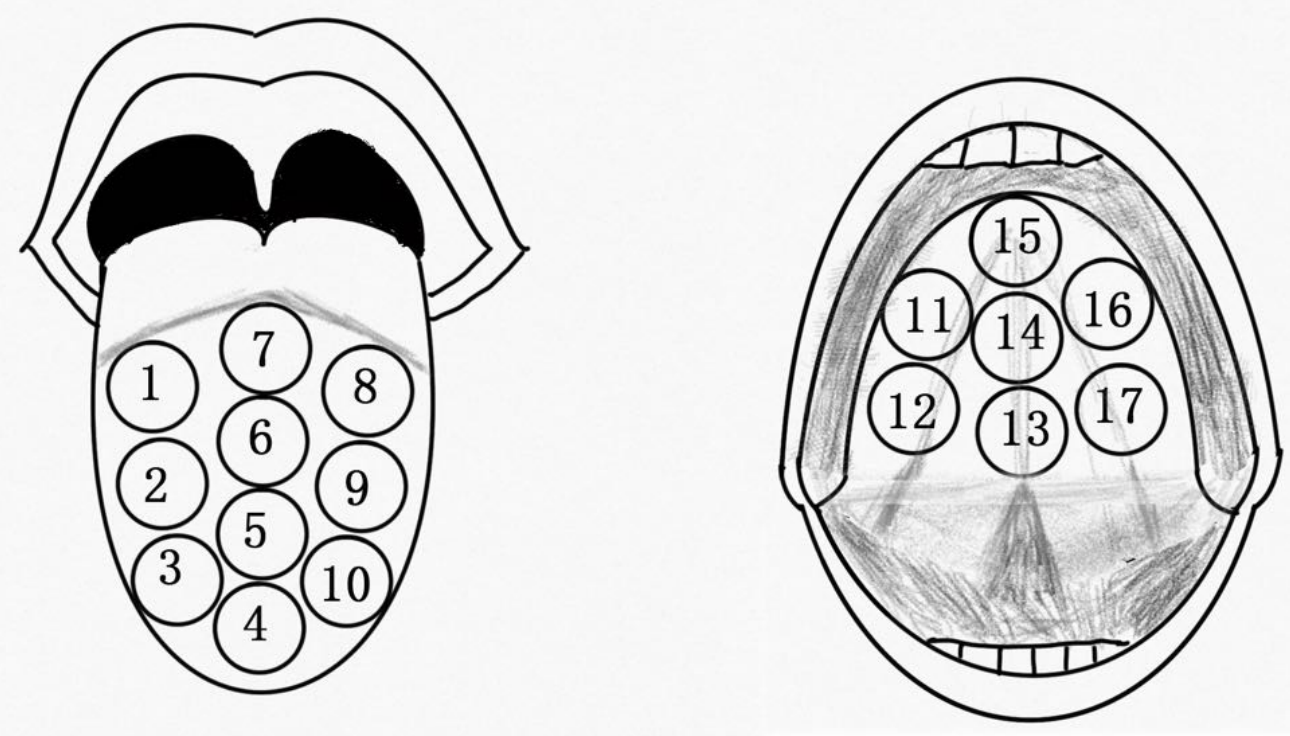

Figure 1

Illustration of irradiation regions of the tongue. 


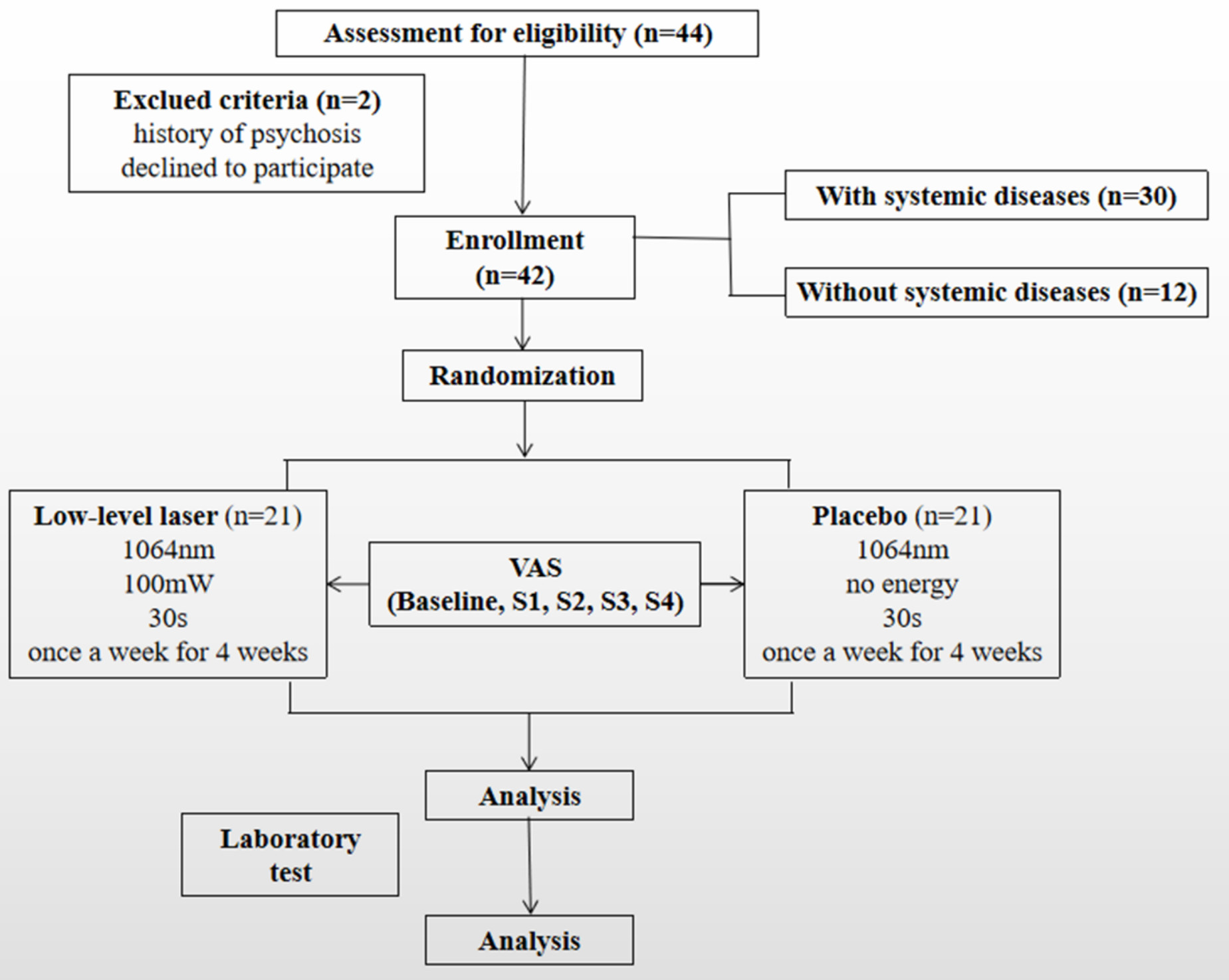

Figure 2

Flow diagram of the trial phases.

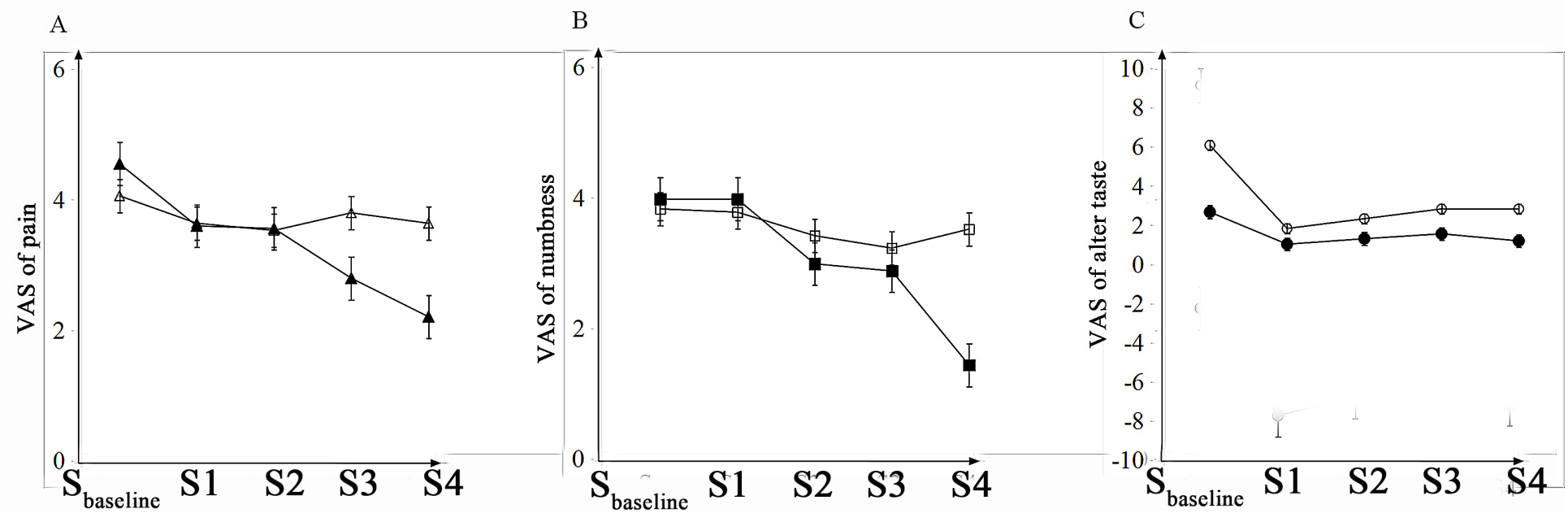




\section{Figure 3}

Improvement of subjective symptom in BMS after treatment between LLL and placebo group. A, VAS of pain; B, VAS of numbness; C, VAS of taste; LLL group, presented as $\mathbf{A}, \mathbf{\square}, \mathbf{0}$; placebo group, presented as $\triangle, \square, 0$.

\section{Supplementary Files}

This is a list of supplementary files associated with this preprint. Click to download.

- Supplementarytable.doc 